\title{
Photocatalytic and Self-Cleaning Properties of Ag-Doped $\mathrm{TiO}_{2}$
}

\author{
B. Tryba*, M. Piszcz and A.W. Morawski
}

West Pomeranian University of Technology, 70-322 Szczecin, Poland

\begin{abstract}
Commercially available $\mathrm{TiO}_{2}$ of anatase structure produced in the Chemical Factory Police S.A. was modified by doping $\mathrm{Ag}$ from $\mathrm{AgNO}_{3}$ solution via photodeposition method. The obtained amount of deposited $\mathrm{Ag}$ on $\mathrm{TiO}_{2}$ was in the range of 0.11 to 0.98 mass \%. Deposition of $\mathrm{Ag}$ on $\mathrm{TiO}_{2}$ resulted in the retarding of the recombination reaction and formation of the higher amount of $\mathrm{OH}$ radicals on the photocatalyst surface during irradiation with UV light. The photocatalytic activity of samples was tested for the decomposition of phenol and Reactive Black in the water solution under both, UV and artificial solar light radiation. Deposition of $\mathrm{Ag}$ on $\mathrm{TiO}_{2}$ surface increased its photocatalytic activity towards the Reactive Black decomposition but not for phenol. High adsorption of Reactive Black on $\mathrm{Ag}$ modified $\mathrm{TiO}_{2}$ photocatalysts, which was higher than on $\mathrm{TiO}_{2}$, could enhance the photocatalytic activity of these samples. The solution with $1 \%$ slurry of $\mathrm{TiO}_{2}-\mathrm{Ag}$ was sprayed on the surface of concrete. For concrete impregnated with $\mathrm{TiO}_{2}-\mathrm{Ag}$ slurry the both, fungicidal and self-cleaning effect for dyes were observed.
\end{abstract}

Keywords: $\mathrm{Ag}$ doped $\mathrm{TiO}_{2}$, self-cleaning, reactive black decolourisation, photocatalysis.

\section{INTRODUCTION}

$\mathrm{TiO}_{2}$ has many applications in the environment. $\mathrm{TiO}_{2}$ under ultraviolet irradiation exhibits photocatalytic activity that enables the oxidative destruction of a wide range of organic compounds (phenols, pesticides, herbicides, dyes, pharmaceutics, organic acids, alcohols, etc.) and biological species (bacteria, viruses, cyanobacteria, algae, and fungi), causing self-decontamination effect [1-4]. In addition, $\mathrm{TiO}_{2}$ exposed under UV exhibits photocatalytically induced superhydrophilicity that converts the hydrophobic character of the surface to hydrophilic and forms the uniform water film, which prevents the adhesion of inorganic or organic components on its surface, which retains clean $[5,6]$. The powdered $\mathrm{TiO}_{2}$ may be deployed on the surfaces of various substrates, such as glass, ceramics, metals, textiles, cement, bricks or fibres to provide layer that exhibits self sterilisation and self cleaning properties, when it is exposed to the light [7-10]. This creates a large commercial potential for $\mathrm{TiO}_{2}$ application: in medicine, automotive and food industries, environmental protection, but especially in the architecture (cultural heritage purposes, facade paints, indoor, wall paper, tiles, etc.).

It has been proved that $\mathrm{TiO}_{2}$ doped with $\mathrm{Ag}$ can sufficiently decompose some dyes and organic acids, such as oxalic and salicylic acids, as well as the other organic compounds, like saccharose, phenol, etc. [11-15]. $\mathrm{TiO}_{2}$ doped with $\mathrm{Ag}$ and mounted on the ceramics can also work as a gas filter for removing some odours like $\mathrm{H}_{2} \mathrm{~S}, \mathrm{CH}_{3} \mathrm{SH}$ or toxic $\mathrm{N}_{2} \mathrm{O}$ gas $[16,17]$. Ag deposited on the surface of $\mathrm{TiO}_{2}$ can prevent the recombination reaction between photogenerated holes and electrons, enhancing the yield of photocatalytic activity of the semiconductor [18]. Nanoparticles of $\mathrm{Ag}$ can also work as a catalyst in the

*Address correspondence to this author at the West Pomeranian University of Technology, 70-322 Szczecin, Poland; Tel: +48 91449 4730; Fax: +48 91449 4656; E-mail: beata.tryba@zut.edu.pl photocatalytic reaction [13]. Some of the photocatalytic oxidation reactions are carried out with simultaneous reduction of $\mathrm{Ag}$ ions during its deposition on the surface of $\mathrm{TiO}_{2}[14,15]$.

In the present work, Ag was deposited on the commercial $\mathrm{TiO}_{2}$ of an anatase structure by the photodeposition method under UV from $\mathrm{AgNO}_{3}$ solution under flow of $\mathrm{Ar}$ gas. The prepared Ag-doped $\mathrm{TiO}_{2}$ have been tested for the decomposition of the Reactive Black and phenol under both, $\mathrm{UV}$, and artificial solar light irradiation. The titania slurry with doped $\mathrm{Ag}$ have been spread on the concrete of the house and the self-cleaning and fungicidal effects have been observed.

\section{MATERIALS AND METHODOLOGY}

\subsection{Photocatalyst Preparation}

Commercially produced $\mathrm{TiO}_{2}$ in Chemical Factory Police S.A. in Poland has been used for preparation. $3 \mathrm{~g}$ of powdered $\mathrm{TiO}_{2}$ has been placed in a quartz beaker together with $\mathrm{AgNO}_{3}$ solution $(75 \mathrm{~mL})$ with different concentrations, $7.4 \cdot 10^{-3}-4.6 \cdot 10^{-4} \mathrm{~mol} / \mathrm{L}$. KOH $(0.1 \mathrm{M})$ was added to obtain $\mathrm{pH}=6.3$. The mixture was magnetically stirred by $15 \mathrm{~min}$, after that $1 \mathrm{~mL}$ of methanol was added and the mixture was rinsed with argon by $45 \mathrm{~min}$. Then UV lamp was switched on and the solution was irradiated for $2 \mathrm{~h}$ with simultaneous flow of argon gas. The obtained Ag-doped $\mathrm{TiO}_{2}$ after photodeposition has been filtered through the membrane filter $0.45 \mu \mathrm{m}$, rinsed with distilled water and dried in oven at $105^{\circ} \mathrm{C}$ for $12 \mathrm{~h}$.

\subsection{Photocatalytic Activity}

The activity of photocatalysts in both visible and UV light was conducted in a beaker filled with $500 \mathrm{ml}$ of phenol $(0.1 \mathrm{~g} / \mathrm{L})$ or Reactive Black $(0.03 \mathrm{~g} / \mathrm{L})$ solutions and photocatalyst $(0.1 \mathrm{~g} / \mathrm{L})$. In case of phenol solution, there was observed almost no adsorption on the photocatalyst surface and reaction was carried out under irradiation for $5 \mathrm{~h}$. In case 
of Reactive Black solution a marked adsorption on the photocatalyst surface has been observed, therefore the photocatalytic reaction has been carried out for $4 \mathrm{~h}$ in the dark until saturation with Reactive Black adsorption, and then the following process of photocatalysis was started by switching the lamp. During adsorption and photocatalytic decomposition the solutions with photocatalyst have been simultaneously mixed with the magnetic stirrer. The concentrations of the phenol and Reactive Black solutions have been analysed in UV-Vis Spectrophotometer by the measure of the absorption light at $\lambda_{\max }=270$ and $597 \mathrm{~nm}$ for phenol and Reactive Black, respectively. Turbidity of the titania slurry solution has been measured each time after photocatalytic process and $10 \mathrm{~min}$ of sedimentation. The prepared Ag-doped $\mathrm{TiO}_{2}$ slurry (1\%) has been painted on the concrete outdoor of the living house. The concrete surface has been cleaned up before painting, moss has been removed. The painting part with Ag-doped $\mathrm{TiO}_{2}$ and the non-painting part have been stained with a dye - Reactive Black. This concrete has been exposed to sunlight. The observations of self-cleaning effects have been done and some photos have been taken to evident this process.

\subsection{Analytical Methods and Techniques}

Content of silver in prepared Ag-doped $\mathrm{TiO}_{2}$ photocatalysts was determined by using inductively coupled plasma atomic emission spectroscopy (ICP-AES) method in ICP-AES Spectrometer (by Jobin - Yvon). The recombination reaction of $\mathrm{TiO}_{2}$ and $\mathrm{Ag}$-doped $\mathrm{TiO}_{2}$ powders was measured by photoluminescence spectra at temperature of liquid nitrogen at excitation wavelength $\lambda=330 \mathrm{~nm}$. The spectra were taken in the Fluorescence Spectrometer Hitachi F-2500 equipped with low temperature sample compartment accessory. Hydroxyl radicals have been detected by using fluorescence technique. Terephthalic acid can easily react with hydroxyl radicals to form highly fluorescence compound, 2-hydroxyterphthalic acid, which is determined in the Fluorescence Spectrometer Hitachi F-2500. For these measurements the photocatalyst samples have been irradiated under UV in the terephthalic acid solution $\left(2 \cdot 10^{-3} \mathrm{M}\right)$ and then the solution, after separation from a photocatalyst was taken to analysis. The fluorescence measurements have been done at the excitation wavelength of $314 \mathrm{~nm}$ and the emission of 330-600 nm with maximum peak at $425 \mathrm{~nm}$. The detailed procedure has been described elsewhere [19].

\section{RESULTS AND DISCUSSION}

Ag-doped $\mathrm{TiO}_{2}$ samples after photodeposition turned to brown colour, which was more intensive when higher concentration of $\mathrm{AgNO}_{3}$ solution was used. After exposition to air, these Ag-doped $\mathrm{TiO}_{2}$ samples became white, probably due to the oxidation process.

In Table $\mathbf{1}$ are presented the results from the ICP measurements, together with the sample names and starting concentration of $\mathrm{AgNO}_{3}$ solutions used for photodeposition. Higher concentration of $\mathrm{AgNO}_{3}$ solution resulted in higher amount of deposited $\mathrm{Ag}$ on $\mathrm{TiO}_{2}$ surface.

Photoluminescence spectra of $\mathrm{TiO}_{2}$ and $\mathrm{Ag}-\mathrm{TiO}_{2}$ photocatalysts measured in a spectrofluorymeter after excitation at $\lambda=330 \mathrm{~nm}$ are shown in Fig. (1). For comparison Ag-doped $\mathrm{TiO}_{2}$ samples with the highest and the lowest contents of Ag were shown. A very broad peak with maximum at around $515 \mathrm{~nm}$ can be observed. The intensity of this peak decreases in the samples with Ag deposition. It is caused by the retarding of the recombination due to the capture of electrons by the $\mathrm{Ag}$ deposited on $\mathrm{TiO}_{2}$ surface. In Fig. (2) the results from the measurements of $\mathrm{OH}$ radicals formation on the photocatalysts surface under UV irradiation are presented. Amount of $\mathrm{OH}$ radicals is increasing with the time of UV irradiation. Insignificant higher amount of $\mathrm{OH}$ radicals was formed on the surface of Ag-doped $\mathrm{TiO}_{2}$ than on the not modified $\mathrm{TiO}_{2}$. Increase of $\mathrm{OH}$ radicals formation on Ag-doped $\mathrm{TiO}_{2}$ samples can be caused by the better separation of free carriers (retarding the recombination reaction in the semiconductor through the capture of electrons by silver deposited on $\mathrm{TiO}_{2}$ ) and enhanced yield of reaction between photogenerated holes and adsorbed water molecules on the photocatalyst surface.

Table 1. Content of $\mathrm{Ag}$ in Ag-Doped $\mathrm{TiO}_{2}$ and Initial Concentrations of $\mathrm{AgNO}_{3}$ Solution Used for Photodeposition

\begin{tabular}{|c|c|c|}
\hline $\begin{array}{c}\text { Concentration of } \mathrm{AgNO}_{3} \\
{[\mathbf{m o l} / \mathbf{L}]}\end{array}$ & $\begin{array}{c}\text { Content of Ag } \\
{[\text { mass \%] }}\end{array}$ & $\begin{array}{c}\text { Sample } \\
\text { Name }\end{array}$ \\
\hline \hline $7.40 \cdot 10^{-3}$ & 0.98 & $\mathrm{Ag} 1$ \\
\hline $3.70 \cdot 10^{-3}$ & 0.68 & $\mathrm{Ag} 2$ \\
\hline $1.85 \cdot 10^{-3}$ & 0.39 & $\mathrm{Ag} 3$ \\
\hline $9.25 \cdot 10^{-4}$ & 0.18 & $\mathrm{Ag} 4$ \\
\hline $4.62 \cdot 10^{-4}$ & 0.11 & $\mathrm{Ag} 5$ \\
\hline
\end{tabular}

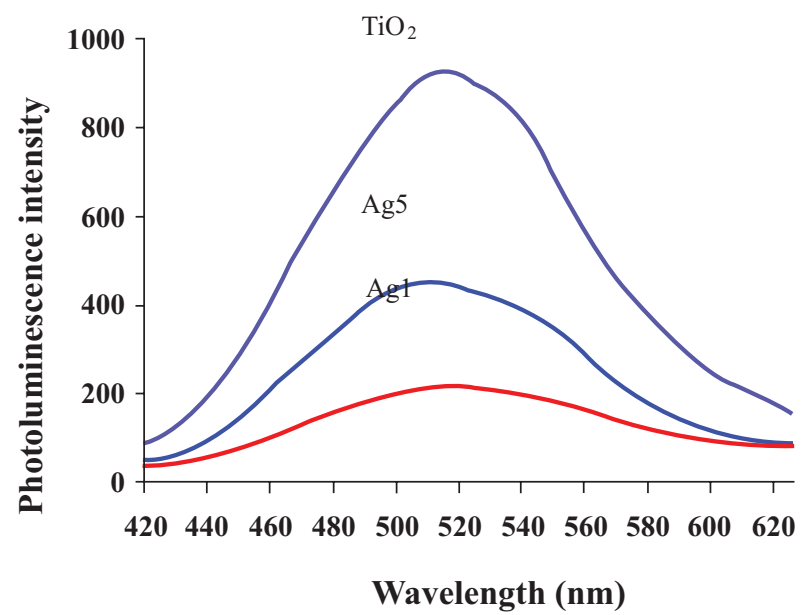

Fig. (1). Photoluminescence spectra of $\mathrm{TiO}_{2}$ and Ag-doped $\mathrm{TiO}_{2}$ photocatalysts.

The photocatalytic decomposition of phenol has been performed on the prepared photocatalysts under UV and artificial solar light irradiation. Results are listed in Table 2. Phenol has been poorly decomposed, either under UV or solar light irradiation, modification of $\mathrm{TiO}_{2}$ by $\mathrm{Ag}$ deposition did not enhance the photocatalytic activity of $\mathrm{TiO}_{2}$.

In Fig. (3) the adsorption and photocatalytic decomposition of Reactive Black under UV and artificial solar light irradiation are presented. High adsorption of 
Reactive Black on the photocatalysts surface has been observed. Modification of $\mathrm{TiO}_{2}$ by silver deposition increased amount of adsorbed dye in Ag-doped $\mathrm{TiO}_{2}$ samples and therefore accelerated the process of dye decomposition. The highest adsorption ability towards Reactive Black had sample Ag3, which also showed the highest rate of Reactive Black decolourisation under UV irradiation. However, under artificial solar light irradiation, Ag1, Ag2, and Ag3 samples showed higher rate of Reactive Black decomposition than $\mathrm{Ag} 4$ and $\mathrm{Ag} 5$ but all of them showed higher decomposition than $\mathrm{TiO}_{2}$.

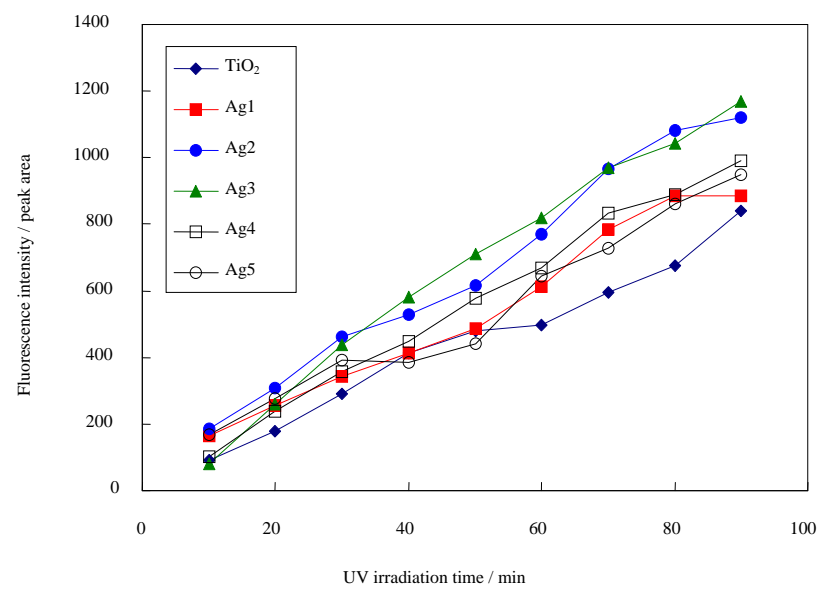

Fig. (2). Formation of $\mathrm{OH}$ radicals on the photocatalysts surface with time of UV irradiation.

Table 2. Phenol Decomposed After $5 \mathrm{~h}$ of $\mathrm{UV}$ and $24 \mathrm{~h}$ of Artificial Solar Light Irradiation

\begin{tabular}{|c|c|c|}
\hline \multirow{2}{*}{ Photocatalyst } & \multicolumn{2}{|c|}{ Phenol Decomposition [\%] } \\
\cline { 2 - 3 } & UV Light (5 h) & Artificial Solar Light (24 h) \\
\hline \hline $\mathrm{TiO}_{2}$ & 13.1 & 11.9 \\
\hline $\mathrm{TiO}_{2}-\mathrm{Ag} 1$ & 14.2 & 8.9 \\
\hline $\mathrm{TiO}_{2}-\mathrm{Ag} 2$ & 13 & 10.2 \\
\hline $\mathrm{TiO}_{2}-\mathrm{Ag} 3$ & 11.3 & 9.5 \\
\hline $\mathrm{TiO}_{2}-\mathrm{Ag} 4$ & 8.2 & 10.8 \\
\hline $\mathrm{TiO}_{2}-\mathrm{Ag} 5$ & 14.2 & 11.3 \\
\hline
\end{tabular}

The solution with $1 \%$ slurry of $\mathrm{Ag}$-doped $\mathrm{TiO}_{2}$ has been used for coating of concrete. The concrete has been stained with a Reactive Black solution on both, the coated and uncoated part and then the self-cleaning effect has been monitored with the time of its exposure in the sunlight. In Figs. $(4,5)$, the photos of the concrete are shown. Both, fungicidal and decolourisation effects can be observed, the part coated with $\mathrm{Ag}$-doped $\mathrm{TiO}_{2}$ became clean with the time of sunlight exposure and also no any moss grew up as it was observed on the uncoated part of concrete in Fig. (5).
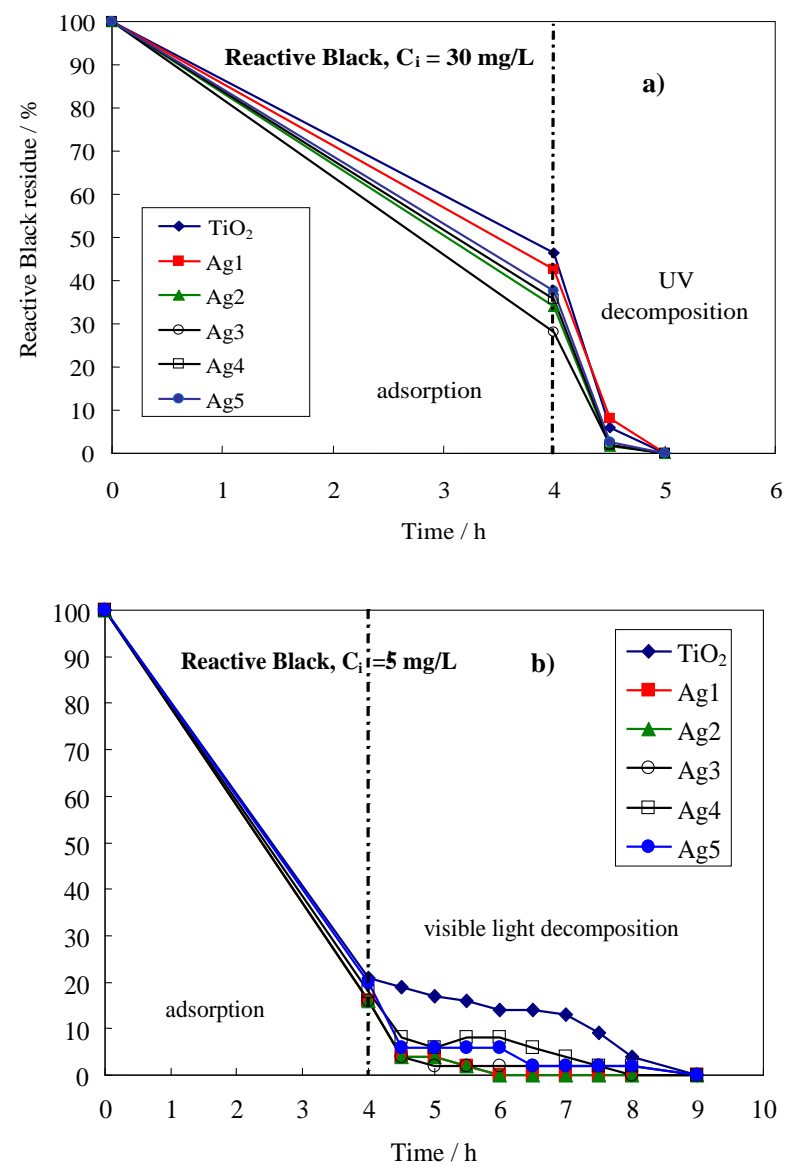

Fig. (3). Reactive Black decomposition on $\mathrm{TiO}_{2}$ and Ag-doped $\mathrm{TiO}_{2}$ photocatalysts under irradiation of a) UV light, and b) artificial solar light.

\section{CONCLUSIONS}

$\mathrm{TiO}_{2}$ was modified by the deposition of $\mathrm{Ag}$ from $\mathrm{AgNO}_{3}$ solution in the amount of 0.11-0.98 mass \%. The presence of $\mathrm{Ag}$ on the surface of $\mathrm{TiO}_{2}$ caused retarding the recombination reaction which occurs after excitation of semiconductor with UV light. Increase of the $\mathrm{OH}$ radicals formation during UV irradiation in Ag-doped samples was observed due to the better separation of free carriers, however there was no linear relation of the photocatalyst ability to $\mathrm{OH}$ radicals formation on the content of $\mathrm{Ag}$ in $\mathrm{TiO}_{2}$. It was probably resulted from the different hydrophility of the samples and the quantity of the adsorbed water molecules on their surface. Deposition of $\mathrm{Ag}$ on $\mathrm{TiO}_{2}$ photocatalyst did not enhance the phenol decomposition, however increased the Reactive Black adsorption on the photocatalyst surface and its decomposition under both, UV and artificial solar light irradiation. It was proved that prepared Ag-doped $\mathrm{TiO}_{2}$ samples can be efficiently used for self-cleaning surfaces, especially for decomposition of stained surfaces, because of their good ability for adsorption of organic dyes and good photocatalytic effects. Sterilizing effect of Ag-doped $\mathrm{TiO}_{2}$ is also a great advantage of this photocatalyst. 

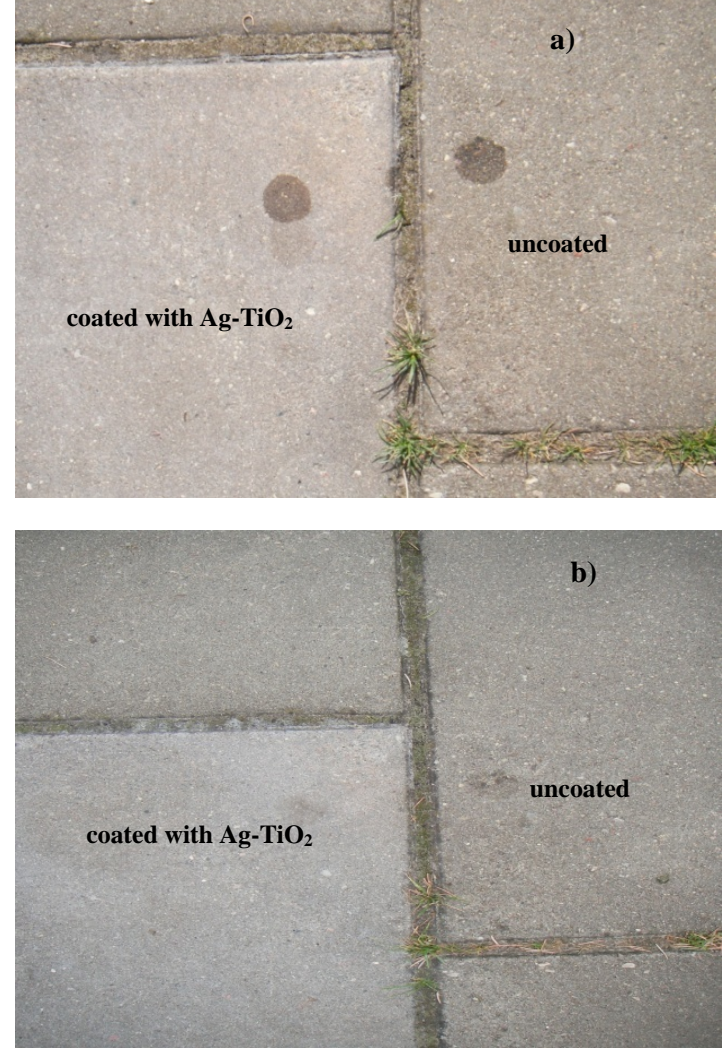

Fig.(4). Photos of the concrete partly coated with titania slurry solution and stained with a dye on the coated and a uncoated parts, a) after stained, and b) after exposure to solar light.

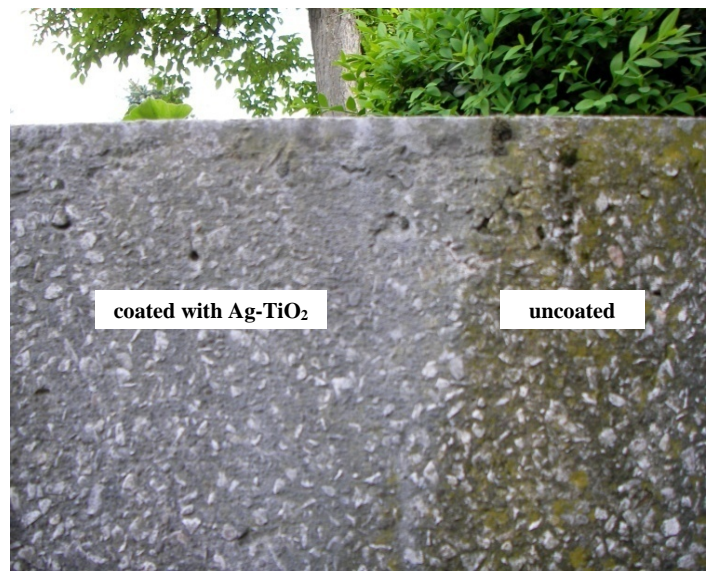

Fig. (5). Photo of concrete partly coated with titania slurry solution $\left(1 \%\right.$ of $\left.\mathrm{Ag}-\mathrm{TiO}_{2}\right)$.

\section{ACKNOWLEDGEMENT}

This work was supported by the research project from the Ministry of Science and Higher Education Nr COST/299/ 2006 for 2007-2010.

\section{REFERENCES}

1] Fujishima A, Hashimoto $\mathrm{K}$, Watanabe $\mathrm{T}$. $\mathrm{TiO}_{2}$ photocatalysis fundaments and applications. BKC Inc 1999.

2] Piera E, Tejedor MI, Zorn ME, Anderson MA. Degradation of chlorophenols by means of advanced oxidation processes: a general review. Appl Catal B Environ 2004; 47: 219-56.

3] Ohko Y, Utsumi Y, Niwa C, et al. Self-sterilizing and self-cleaning of silicone catheters coated with $\mathrm{TiO}_{2}$ photocatalyst thin films: a preclinical work. J Biomed Mater Res 2001; 58: 97-101.

4] Pratap RM, Venugopala A, Subrahmanyam M. Hydroxyapatitesupported $\mathrm{Ag}-\mathrm{TiO}_{2}$ as Escherichia coli disinfection photocatalyst. Water Res 2007; 41: 379-86.

5] Zubkov T, Stahl D, Thompson TL, Panayotov D, Diwald O, Yates JT. Ultraviolet light-induced hydrophilicity effect on $\mathrm{TiO}_{2}(110)(1 \times 1)$. Dominant role of the photooxidation of adsorbed hydrocarbons causing wetting by water droplets. J Phys Chem B 2005; 109: 15454-62.

Gao Y, Masuda Y, Koumoto K. Light-excited superhydrophilicity of amorphous $\mathrm{TiO}_{2}$ thin films deposited in an aqueous peroxotitanate solution. Langmuir 2004; 20: 3188-94.

Yuranova T, Mosteco R, Bandara J, Laub D, Kiwi J. Self-Cleaning cotton textiles surfaces modified by photoactive $\mathrm{SiO}_{2} / \mathrm{TiO}_{2}$ coating. J Mol Catal A Chem 2006; 244: 160-7.

Sanchez B, Coronado JM, Candal R, et al. Preparation of $\mathrm{TiO}_{2}$ coatings on PET monoliths for the photocatalytic elimination of trichloroethylene in the gas phase. Appl Catal B Environ 2006; 66: 295-301.

Hidalgo MC, Sakthivel S, Bahnemann D. Highly photoactive and stable $\mathrm{TiO}_{2}$ coatings on sintered glass. Appl Catal A Gen 2004; 277: 183-9.

Hashimoto $\mathrm{K}$, Irie $\mathrm{H}$, Fujishima A. $\mathrm{TiO}_{2}$ photocatalysis: A historical overview and future prospects. Jpn Soc Appl Phys 2005; 44: 8269-85.

Sobana N, Murugandham M, Swaminathan M. Nano-Ag particles doped $\mathrm{TiO}_{2}$ for efficient photodegradation of Direct azo dyes. J Mol Catal A Chem 2006; 258: 124-32.

12] Arabatzis IM, Stergiopaulos T, Bernard MC, Labou D, Neophytides SG, Falaras P. Silver-modified titanium dioxide thin films for efficient photodegradation of methyl orange. Appl Catal B Environ 2003; 42: 187-201.

Vamatheron V, Amal R, Beydoun D, Low G, McEroy S. Photocatalytic oxidation of organics in water using pure and silvermodified titanium dioxide particles. J Photochem Photobiol A Chem 2002; 148: 233-45.

Szabo-Bárdos E, Czili H, Horváth A. Photocatalytic oxidation of oxalic acid enhanced by silver deposition on a $\mathrm{TiO}_{2}$ surface. J Photochem Photobiol A Chem 2003; 154: 195-201.

Dobosz A, Sobczyński A. The influence of silver additives on titania photoactivity in the photooxidation of phenol. Water Res 2003; 37: 1489-96.

Kato S, Hirano Y, Iwata M, Sano T, Takeuchi K, Matsuzawa S. Photocatalytic degradation of gaseous sulfur compounds by silverdeposited titanium dioxide. Appl Catal B Environ 2005; 57: 10915 .

Sano T, Negishi N, Mas D, Takeuchi K. Photocatalytic decomposition of $\mathrm{N}_{2} \mathrm{O}$ on highly dispersed $\mathrm{Ag}^{+}$ions on $\mathrm{TiO}_{2}$ prepared by photodeposition. J Catal 2000; 194: 71-9.

Ilisz I, Dombi A. Investigation of photodecomposition of phenol in near - UV-irradiated aqueous $\mathrm{TiO}_{2}$ suspensions. II. Effect of charge-trapping species on product distribution. Appl Catal A Gen 1999; 180: 35-45.

Ishibashi K, Fujishima A, Watanabe T, Hashimoto K. Detection of active species in $\mathrm{TiO}_{2}$ photocatalysis using the fluorescence technique. Electrochem Commun 2000; 2: 207-10. 